\title{
Explosive Risk Evaluation of LPG Tank under Fire Based on Comprehensive Evaluation Algorithm
}

\author{
Hong gang Cai, Bin Zhao ${ }^{a, *}$, Ming shuo Yang \\ School of mechanical engineering, Liaoning Shihua University, Fushun, Liaoning 113001, China \\ azbzbz0203288@163.com \\ ${ }^{*}$ corresponding author
}

Keywords: risk evaluation, LPG tank, grey relational algorithm, fire.

\begin{abstract}
The explosive risk evaluation of LPG tank under fire is important for putting forward the safety measurement, in order to improve the evaluation correctness, and the fisher fishing algorithm and the grey relational analysis are applied in it. Firstly, the explosion characteristics of LPG tank under fire are discussed. Secondly, the basic theory of fisher fishing algorithm and grey relational analysis are studied. Thirdly, explosive risk evaluation simulation of LPG tank under fire are carried out based on the comprehensive algorithm, and results show that new evaluation method can evaluate the explosive risk of LPG under fire effectively.
\end{abstract}

\section{Introduction}

LPG (Liquefied Petroleum Gas) is the hydrocarbon containing small amounts of carbon atoms obtained during the procession of petroleum refining, which is important fuel and chemical substances. However the explosion limit of LPG only ranges from $1.5 \%$ to $9.5 \%$. LPG is flammable and explosive, which has extreme potentially hazardous during the procession of storage and transportation. The explosion and fire of LPG tank under fire is often caused by many factors, therefore it is necessary to find out an effective evaluation method for evaluating explosive risk of LPG tank under fire. There are some traditional evaluation methods, such as table checking method, accident tree analysis method, the traditional evaluation methods can find out hidden trouble of LPG tank under fire, but these evaluation methods have difficulty in quantitatively describing all factors. The security of LPG tank under fire belongs to a complex man-machine system with multiple factor, multivariate and multi-level. It is necessary to find out an effective evaluation method for evaluating explosive risk of LPG tank under fire, and then the correct evaluation results can be obtained, which can offer effective theoretical basis for establishing risk prevention measures of LPG tank. The entropy evaluation method and analytic hierarchy process are used to evaluate all factors of LPG tank under fire, in order to improve rationality of weight value, and an advanced algorithm should be used to carry out the optimization of the results from the entropy evaluation method and analytic hierarchy process respectively. The fisher fishing algorithm can be applied in confirming the optimal weight, the grey relational analysis can obtain the relational degree between every factor and safety of LPG tank under fire, then the mistake due to subjective factors can be reduced, then the value of weight is reasonable [1].

\section{Explosion characteristics of LPG tank under fire}

LPG is made up of propane, normal butane, propylene and 1-butene. The fire danger class of LPG is A, LPG has low flash point, little minimum ignition energy, little low explosive limit and big explosive range. The gasification of LPG generates easily under at ordinary temperatures and pressure, the volume of LPG expands 250-350 times quickly, and LPG is easy to gather in a hollow, or spreads along the earth's surface. LPG will burn or even explode when it encounters the fire.

Flame temperature of LPG reaches $2273 \mathrm{~K}$, the caloric power of it is higher than other fuels, and the explosive speed is $2000-3000 \mathrm{~m} / \mathrm{s}$. Combustion and explosion of LPG can generate strong thermal 
radiation and tremendous shock wave overpressure, the corresponding destructive effect is every strong. LPG has high coefficient of expansion, in closed container, temperature rise will lead to the obvious improvement of pressure, and then the physical explosion will happen [2].

\section{Basic theory of fisher fishing algorithm and grey relational analysis}

Fisher $i$ begins to carry out contacting strategy in $m$ th time for fishing. When the contacting times of fisher reaches the predefined threshold and does not reach the new position with bigger density of fish, and then fisher $i$ may fall into local optimal region. According to this problem, the accelerating jumping mechanism of fisher is set. When searching times of fisher $i$ in position $P_{m}^{(i)}$ reaches threshold and the following conditions are satisfied [3]:

$$
\begin{aligned}
& f\left(P_{m}^{(i)}\right) \geq \max _{X(i) \in \Omega_{m}^{(i)}} f\left(X^{(i)}\right) \\
& f\left(P_{m}^{(i)}\right)<\max \left\{f\left(P_{m}^{(i)}, 1,2, \cdots, k\right\}\right.
\end{aligned}
$$

Then fisher $i$ does not find out the point with bigger density of fish in the block constructed by themselves, however positions of other fishers may exist the point with bigger density of fish, then fisher $i$ jumps the current position quickly. A point is originated randomly in fishing region again; the mobile and contacting strategies are carried out repeatedly, if the following conditions are satisfied:

$$
\begin{aligned}
& f\left(P_{m}^{(i)}\right) \geq \max _{X(i) \in \Omega_{m}^{(i)}} f\left(X^{(i)}\right) \\
& f\left(P_{m}^{(i)}\right) \geq f\left(P_{m}^{(i)}\right), f\left(P_{m}^{(i)}\right) \geq \max _{X(i) \in \Omega_{m}^{(i)}} f\left(X^{(i)}\right)
\end{aligned}
$$

Then the position of fisher $i$ is the global optimal. The weight of every evaluation index can be obtained based on fisher fishing optimization algorithm.

(2) Grey relational degree analysis of evaluating indexes

The main steps are listed as follows:

Step 1: Standard processing is carried out. Every data is standardized as data between zero and one taking reference sequence as reference point.

Step 2: the relational coefficient is calculated. There are several comparing sequences $X_{1}, X_{2}$, $\cdots, X_{n}$ for a reference sequence $X_{0}$. The relational coefficient $\varepsilon(k)$ at any moment between every comparing sequence and reference sequence can be calculated by the following expression [4]:

$$
\varepsilon(k)=\frac{\min _{i} \min _{k}\left|X_{0}(k)-X_{i}(k)\right|+\rho \max _{i} \max _{k}\left|X_{0}(k)-X_{i}(k)\right|}{\left|X_{0}(k)-X_{i}(k)\right|+\rho \max _{i} \max _{k}\left|X_{0}(k)-X_{i}(k)\right|}
$$

where $\rho$ denotes the resolution ratio, $0<\rho<1, \rho=0.6$ in this research.

Step 3: the relational degree is calculated. In order to facilitate the whole comparison, it is necessary to set every evaluation index as a value, therefore the weighted average of evaluation indexes is used as relational degree, which is expressed as follows [5]:

$$
r_{i}=\sum_{j=1}^{n} \omega_{j}^{\prime} \varepsilon_{i}(k)
$$

Where $\omega_{j}^{\prime}$ denotes the optimization weight. The comparison between two relational degrees is carried out. The bigger the relational degree is, the safer the LPG tank under fire is.

\section{Case study of explosive risk of LPG tank under fire}

The LPG tank in a LPG station is used as an example the explosive risk evaluation of LPG tank under fire is carried out based on fisher fishing weight optimization algorithm and grey relational analysis. There are four LPG tanks with volume of $120 \mathrm{~m}^{3}$, twelve experts are invited to grade the explosive risk of LPG tank. According to the real situation of LPG station, the corresponding 
explosive risk evaluation index system of LPG tank under fire is established, which is shown in table 1.

Table 1 Evaluation index system of LPG tank under fire

First level index

Integrated management of LPG tank $\left(\mathrm{A}_{1}\right)$

Operation environment of LPG tank $\left(\mathrm{A}_{2}\right)$

Real situation of fireproofing $\left(\mathrm{A}_{3}\right)$

Passive fire protection capacity of LPG tank $\left(\mathrm{A}_{4}\right)$

Active fire protection ability of LPG tank $\left(\mathrm{A}_{5}\right)$
Second level index

Organization $\left(\mathrm{A}_{11}\right)$

Planned technical measures for safe $\left(\mathrm{A}_{12}\right)$

Safety management system $\left(A_{13}\right)$

Implementation of system $\left(\mathrm{A}_{14}\right)$

Workplace $\left(\mathrm{A}_{21}\right)$

Environmental condition $\left(\mathrm{A}_{22}\right)$

Shared device $\left(\mathrm{A}_{23}\right)$

Leakage detection device $\left(\mathrm{A}_{31}\right)$

Fire water supply system $\left(\mathrm{A}_{32}\right)$

Foam installation $\left(\mathrm{A}_{33}\right)$

Portable extinguisher $\left(\mathrm{A}_{34}\right)$

Fire compartment design $\left(\mathrm{A}_{41}\right)$

Fire partition $\left(\mathrm{A}_{42}\right)$

Electrical fire protection equipment $\left(\mathrm{A}_{43}\right)$

Automatic monitoring alarm system $\left(\mathrm{A}_{51}\right)$

Sprinkler system $\left(\mathrm{A}_{52}\right)$

Fire extinguishing system $\left(\mathrm{A}_{53}\right)$

The evaluation index is assigned according to five grades. The five grades are very poor, poor, common, good and very good respectively, and the score ranges from 1 to 5 . The questionnaires are granted to management and maintain experts of LPG tank, and the scores of withdraw questionnaires are used as original data for computing weight. In order to evaluate the effectiveness of the fisher fishing algorithm, the particle algorithm and genetic algorithm are also used to carry out weight optimization.

The LPG station takes five explosion proof plans, and the whole relational degree of every plan can be calculated based on the relationship degree analysis model, the corresponding calculating results are shown in table 2.

Table 2. Whole relationship degree for every explosion proof plan

\begin{tabular}{cc}
\hline Plan & Whole relationship degree $r_{i}$ \\
\hline Plan 1 & 0.735 \\
Plan 2 & 0.682 \\
Plan 3 & 0.775 \\
Plan 4 & 0.832 \\
Plan 5 & 0.691 \\
\hline
\end{tabular}

As seen from table 3, the whole relationship degree of plan 4 is biggest, and then the explosive risk of LPG tank corresponding to plan 4 is biggest. While the whole relationship degree of plan 2 is lest, and then the explosive risk of LPG tank corresponding to plan 4 is lest. Therefore the plan 2 is best means for preventing the explosion of LPG, which can be chosen in LPG station. According to the analysis results, the corresponding measurements can be taken from integrated management, operation environment, fireproofing situation, passive fire protection capacity and active fire protection ability, and then the fire and explosion accidents of LPG tank under fire can be avoided effectively. 


\section{Summary}

According to real situation of LPG tank under fire, the explosive risk evaluation index system of LPG tank under fire is established. The fisher fishing weight optimization algorithm is used to confirm the weight of every evaluation index with entropy evaluation method and analytic hierarchy process, confirming the weight subjectively and objectively during the procession of evaluation can be avoided, the optimal processing is carried out for confirming the weight of every evaluation index, then the rationality of confirming the weight of evaluation index can be ensured, then the reliability of the evaluation results can be improved. Numerical analysis is carried out for a LPG station, and the explosive risk of LPG tank under fire is evaluated effectively, the evaluation results can offer theoretical guidance for confirming the optimal fireproof plan, the economic damages and casualties due to fire and explosion of LPG tank under fire can be avoided effectively.

\section{Acknowledgements}

This research was supported by the national natural science foundation (51206075).

\section{References}

[1] Zhang Zhi, Meng Shao-ping, Zhou Zhen, Zhu Yazhi. Numerical integration method of acceleration recodes for shaking table test, Journal of Vibration, Measurement and Diagnosis, Vol. 33 (2013), No.4, p.627-633.

[2] Birk, A.M., Cost-Effective Application of Thermal Protection on LPG Road Transport Tanks for Risk Reduction Due to Hot BLEVE Incidents, Risk Analysis, Vol.34 (2014), No.6, p.1139-1148.

[3] Runchun Han, Jixian Xiao, Jie Yang, Hongwei Du, Deciding weighing by entropy evaluation method is an error, Journal of Theoretical and Applied Information Technology, Vol.48 (2013), No.3, p. $1738-1742$.

[4] Gros\&caron elj P., Stirn L.Z., Ayrilmis N., Kuzman M.K., Comparison of some aggregation techniques using group analytic hierarchy process, Expert Systems with Applications, Vol.42 (2015), No.4, pp.2198-2204.

[5] Qixu Liu, Yuqing Zhang, Ying Kong, Qianru Wu, Improving VRSS-based vulnerability prioritization using analytic hierarchy process, Journal of Systems and Software, Vol.85 (2012), No.8, p.1699-1708. 